\title{
CONSELHO MUNICIPAL DE EDUCAÇÃO EM MOSSORÓ-RN: UM ESTUDO SOBRE SUA FUNÇÃO DELIBERATIVA
}

\author{
MUNICIPAL COUNCIL OF EDUCATION IN MOSSORÓ-RIO GRANDE DO NORTE, BRAZIL: \\ A STUDY OF ITS DELIBERATIVE FUNCTION
}

CONSEJO MUNICIPAL DE EDUCACIÓN EN MOSSORÓ-RN: UN ESTUDIO SOBRE SU FUNCIÓN DELIBERATIVA

Allan Solano Souza ${ }^{1}$

Arilene Maria Soares de Medeiros²

${ }^{1}$ Doutor em Educação pela UFRN. Docente do Departamento de Educação da Universidade do Estado do Rio Grande do Norte (UERN), Mossoró, RN, Brasil.

²Doutora em Educação pela UFSCar. Docente do Programa de Pós-Graduação em Educação da Universidade do Estado do Rio Grande do Norte (UERN), Mossoró, RN, Brasil.

Resumo: Este artigo analisa como acontece a tomada de decisão no Conselho Municipal de Educação de Mossoró-RN, órgão colegiado que subsidia diretamente a Secretaria Municipal de Educação na implementação, na discussão e nos encaminhamentos da política municipal. Com base na abordagem qualitativa, a pesquisa envolve seis representantes titulares do referido conselho com a realização de entrevista semiestruturada individual. A análise dos dados se fundamenta nos aportes da análise do conteúdo. Identifica-se que as reuniões e as pautas consistem em um primeiro aspecto da tomada de decisão, seguindo-se de um processo de conscientização dos sujeitos sobre as decisões a serem colocadas em prática por meio do voto da maioria. Todavia, conclui-se que o conselho tem se revelado como um órgão de controle estatal, decidindo mais sobre assuntos da Secretaria Municipal de Educação, ao afirmar que a Lei de Responsabilidade Educacional foi a decisão que mais beneficiou a educação no município, e deixando marginalizada a importância do Plano Municipal de Educação, mesmo que reconheça sua autonomia relativa para decidir e considere que foi instituído como mecanismo de democratização. Palavras-chave: Democratização; Conselho Municipal de Educação; Tomada de Decisão.

Abstract: This article analyzes the decision-making process of the Municipal Council of Education of Mossoró in Rio Grande do Norte, Brazil. The Municipal Council of Education is a collegiate body that directly supports the Municipal Secretary of Education in the implementation, discussion and referral of municipal policies. Based on a qualitative approach, this study involves individual and semi-structured interviews with six representatives of the said council. The data were analyzed based on the contributions of content analysis. It was identified that meetings and guidelines represent an initial stage of decisionmaking, followed by a process of raising awareness of the subjects about the decisions to be put into practice through the majority vote. However, it is concluded that the council has been revealed as state control body, deciding more on matters of the Municipal Secretary of Education, by stating that the Law of Educational Responsibility was the decision that most benefited education in the municipality, relegating the Municipal Education Plan to a place of lesser importance, although it recognizes its relative autonomy to decide, and believes that it was instituted as a democratization mechanism.

Keywords: Democratization; Municipal Council of Education; Decision Making 
Resumen: Este artículo analiza cómo ocurre la toma de decisión en el Consejo Municipal de Educación de Mossoró-RN, órgano colegiado que subsidia directamente a la Secretaría Municipal de Educación en la implementación, discusión y encaminamientos de la política municipal. Con base en el abordaje cualitativo, la investigación involucra a seis representantes titulares de dicho consejo con la realización de una entrevista semiestructurada individual. El análisis de los datos se fundamenta en los aportes del análisis del contenido. Se identifica que las reuniones y las pautas consisten en un primer aspecto de la toma de decisión, seguido de un proceso de concientización de los sujetos sobre las decisiones a ser puestas en práctica por medio del voto de la mayoría. Sin embargo, se concluye que el consejo se ha revelado como un órgano de control estatal, decidiendo más sobre asuntos de la Secretaría Municipal de Educación, al afirmar que la Ley de Responsabilidad Educacional fue la decisión que más benefició a la educación en el municipio, y dejando marginada la importancia del Plan Municipal de Educación, aunque reconozca su autonomía relativa para decidir y considere que fue instituido como mecanismo de democratización.

Palabras clave: Democratización; Consejo Municipal de Educación; Tomada de Decisión.

\section{INTRODUÇÃO}

Os Conselhos Municipais de Educação (CME) se configuram como órgãos colegiados de suma importância para a gestão da educação no município e como articuladores dos processos de formulação, acompanhamento e deliberação de políticas educacionais. Sua trajetória na educação brasileira revela mais uma possibilidade de descentralização do poder de decisão nos sistemas municipais de ensino, cujas características sofrem variações de um município para o outro, entretanto, possuem traços comuns em relação às suas funções, sendo fiscalizador, propositivo, deliberativo, avaliador, entre outros. Há ainda aqueles que desempenham um papel que se mistura com a responsabilidade das secretarias de educação, nos casos em que são considerados como normativos. Nesse aspecto, o CME confunde-se como braço da secretaria, influenciando diretamente na forma como esse órgão decide em favor de quem decide e quais são os critérios utilizados no processo de tomada de decisão.

Este artigo tem como objetivo apresentar alguns aspectos do processo da tomada de decisão no Conselho Municipal de Educação de Mossoró-RN (1997-2010), que está sendo considerado órgão colegiado híbrido, subsidiando diretamente a Secretaria Municipal de Educação na implementação, na discussão e nos encaminhamentos da política educacional local. A metodologia escolhida para este momento tem seus fundamentos na abordagem qualitativa, conforme Bogdan e Biklen (1994), pois se compreende que, com base nela, é possível encontrar caminhos necessários à análise do problema em profundidade, com respaldo teórico e pesquisa empírica.

Nesse sentido, tomou como base estudos sobre a legislação municipal e entrevistas semiestruturadas com seis (06) representantes titulares do Conselho Municipal de Educação de Mossoró (CME), que são denominados de R1, R2, R3, R4, R5 e R6, resguardando o anonimato dos entrevistados. O recorte temporal deste estudo tem como ponto de partida o período de reorganização democrática brasileira, após a aprovação da Constituição Federal de 1988, e seus desdobramentos nas décadas seguintes. A fundamentação teórica deste trabalho corrobora o debate sobre a teoria política, na medida em que discute as mudanças nas relações entre 
Estado e sociedade, tendo por base autores como Lenhardt e Offe (1984), Bobbio $(2006,2010)$ e Santos e Avritzer (2002). A partir desses referenciais, ainda se concebe o conselho como via de representação, participação e deliberação, por se considerar que não há uma visão única e contrária à ideia que o defende como mecanismo de burocratização.

Os pressupostos legais que norteiam o CME-Mossoró-RN foram buscados a partir da sua institucionalização no município, para tanto, os documentos da política educacional são de suma importância, pois são considerados dados preexistentes necessários no processo de democratização da gestão da educação. Nesse sentido, foram realizadas as análises do Regimento Interno do Conselho Municipal de Educação de Mossoró-RN (1997), da Lei 1.109/1997, que cria o Sistema Municipal de Ensino e elenca o CME como órgão do sistema, e da Lei 1.110/1997, que cria o conselho. Concomitante a esse processo, houve a realização de entrevistas semiestruturadas, priorizando neste artigo as questões que discutem diretamente a tomada de decisão no conselho. Como técnica de análise, recorreu-se à análise de conteúdo, seguindo as orientações expostas por Bardin (1977), Franco (2008), Janeira (1972) e Moraes (1999), na medida em que propõem a criação de unidades de referência, categorização e inferências em relação aos documentos e aos discursos produzidos pelos sujeitos da pesquisa.

Este artigo está composto de duas seções. Na primeira, discute-se sobre os Conselhos Municipais de Educação, pensando em suas funções e no poder de decisão, cuja construção da democratização se vincula à Constituição de 1988 e seus desdobramentos se materializam no âmbito das políticas educacionais. Na segunda, aborda-se o conjunto de dados construídos empiricamente a partir da leitura e da análise da legislação local, que enfatizam a democratização da gestão no âmbito do sistema, e da participação de seis conselheiros titulares mediante a realização de entrevista semiestruturada.

\section{Da Democratização da Sociedade Brasileira aos Conselhos Municipais de Educação}

As mudanças que ocorreram na relação Estado/sociedade nas últimas décadas do século XX e na primeira década do XXI foram sintomáticas no sentido do reconhecimento da democracia não apenas do ponto de vista da representação, mas também da participação dos sujeitos sociais nos processos decisórios. Nesse caso, a participação é concebida como estratégia política capaz de propiciar o aprimoramento da democracia e viabilizar o aperfeiçoamento dos processos de tomada de decisão, de acordo com Santos e Avritzer (2002). Diante disso, o Conselho Municipal de Educação não se esgota como mecanismo da democracia representativa, o que, geralmente, acontece, mas como possibilidade de participação de diferentes setores da sociedade nas decisões cruciais que envolvem o sistema municipal de ensino.

Uma discussão sobre os Conselhos Municipais de Educação requer reflexões à luz de referenciais teóricos que abordem a relação entre Estado, democracia e sociedade. No caso brasileiro, algumas considerações a mais são necessárias, uma vez que, a partir do contexto da aprovação da Constituição Federal de 1988, os municípios passam a gozar de maior autonomia para organizar seus sistemas municipais de ensino ${ }^{1}$, resguardando os princípios 
constitucionais e os seus limites legislativos. Nesse cenário, esses entes federados aumentam suas responsabilidades com seu sistema de educação, o que se torna uma das maiores inovações para a esfera do poder local no estabelecimento de normas, vindo ao encontro de uma política municipalista em voga, conforme explicita Ribeiro (2004).

Nesse sentido, essa consideração se faz necessária, diante das características que são particulares do federalismo brasileiro, ao incorporar o município como ente à sua organização política. Entretanto, esse processo possui algumas limitações, dentre as quais se destacam as dificuldades que os municípios brasileiros enfrentam para assumir os compromissos administrativos e financeiros, sobrevivendo à espera de recursos transferidos dos estados e/ ou da União, que também devem contribuir por meio da cooperação técnica.

Ora, a década de 1990 é decisiva para a efetivação dos Conselhos Municipais de Educação no Brasil, principalmente porque esse decênio traz conquistas importantes para a realidade brasileira, especialmente em termos educacionais, embora sua natureza histórica seja muito anterior a esse período, pois é no Rio Grande do Sul que as experiências com o ensino se iniciam, reportando-se ao período imperial. É nesse contexto de abertura que crescem as possibilidades da democratização da educação via municipalização, como estratégia de descentralização.

Em consonância com Ribeiro (2004), os Conselhos Municipais de Educação são estratégicos, principalmente ao se considerarem suas funções básicas no âmbito dos sistemas de ensino: consultivas, normativas, deliberativas e fiscalizadoras. Dentre elas, este trabalho focaliza na função deliberativa, que consiste na tomada de decisão. A função deliberativa pode contribuir para compreender como esse mecanismo se efetiva como mecanismo de democratização das relações nesse colegiado. A organização de uma reflexão sobre o processo de tomada de decisão não é tarefa fácil, tendo em vista os condicionantes que o subjazem, porém surge como possibilidade de democratização da gestão no âmbito dos sistemas municipais de ensino.

Do ponto de vista histórico, os CMEs se desenvolvem ao lado dos demais conselhos de educação, tais como o Conselho do FUNDEF (FUNDEB), o Conselho de Alimentação Escolar, os Conselhos de Escola, entre outros. Em uma pesquisa realizada pelo Instituto Brasileiro Geográfico de Estatísticas (IBGE) sobre os municípios brasileiros, verifica-se a expansão dos Conselhos de Educação, cuja realidade vem se alterando ano a ano. Nesse sentido, um dos seus recortes ressalta:

A MUNIC registra o crescimento no número de municípios que declararam possuir Conselho de Educação local, passando de $68,0 \%$, em 2006 , para $79,1 \%$ do total, em 2009. No mesmo intervalo, o percentual de conselhos com constituição paritária salta de $48,0 \%$ para $70,8 \%$, bem como a indicação de conselhos com caráter consultivo passa de $53,0 \%$ para $64,8 \%$, com caráter deliberativo vai de $51,0 \%$ para $65,0 \%$, com função normativa sai de $41,0 \%$ para $51,1 \%$ e de perfil fiscalizador vai de $49,0 \%$ para $60,0 \%$ [...]. Sobre estes dados, parece coerente que o Conselho Municipal de Educação seja chamado a desempenhar mais e mais amplas funções, na medida em que assume verdadeiro papel de agente do poder administrativo. (IBGE, 2010, p. 51).

Nesse contexto, a trajetória dos conselhos de educação local se confunde com a história dos Conselhos Municipais de Educação. A lógica do crescimento não se circunscreve apenas ao número de conselhos, mas também em relação à sua constituição paritária e às suas funções. Quanto à função deliberativa, verifica-se que passou de 51\%, em 2006, para 65\%, em 2009. Portanto, em três anos, há um acréscimo de $14 \%$ com caráter deliberativo. Em suma, os conselhos vão se aprimorando no que diz respeito à democratização da gestão, na medida em que suas funções também vão se ampliando e, ao mesmo tempo, a própria sociedade vai 
alargando sua compreensão de democracia. Ou seja, a democracia representativa se mantém, mas apresenta limites, o que sugere, portanto, iniciativas de democracia participativa, como defendem Santos e Avritzer (2002).

Nessa mesma pesquisa, o IBGE registra que os CMEs têm concentrado suas ações em diferentes áreas educacionais, dentre elas: capacitação de professores; diminuição da evasão escolar; regulamentação e valorização da carreira do magistério; melhoria do transporte escolar; campanha para matricular as crianças na escola; participação da comunidade na gestão da escola; melhoria ou implementação de programas na assistência escolar; contratação de professores; investimentos em organizações administrativas; ampliação de atendimento a alunos com necessidades especiais; desenvolvimento de projetos para a Educação de Jovens e Adultos; autonomia financeira da escola; estabelecimento de projetos para a educação do campo, indígena e ambiental; desenvolvimento de projetos para a promoção de uma educação racista; e instituição de curso profissionalizante.

Esse mesmo documento afirma que os municípios indicam baixa sinergia nas relações interinstitucionais com os diversos atores da educação local ${ }^{2}$. Essa realidade retrata; em certa medida; como funcionam determinados sistemas municipais de educação quando implantam em sua organização mecanismos de controle social, como o Conselho Municipal de Educação. No jogo democrático, as regras referentes à tomada de decisão, na maioria das vezes, não são muito claras para os atores envolvidos, o que é um dos grandes desafios para os Conselhos Municipais de Educação.

Além disso, é preciso considerar consensos e conflitos como construções. A homogeneidade não existe em sociedades democráticas, principalmente nas democracias mais consolidadas, que exigem o reconhecimento da heterogeneidade como marca social maior e o diálogo. A efetivação do diálogo é um dos exercícios a serem feitos na perspectiva da inclusão e da participação dos diferentes atores em sua singularidade. A convivência com a diferença de opiniões e a sua administração consistem em desafios para as sociedades democráticas na contemporaneidade.

O pensamento que norteia essa construção procura ter como base a possibilidade de participação efetiva. Sendo assim, a superação da ideia dos Conselhos Municipais de Educação como aparelho de controle subordinado à administração pública local ${ }^{3}$ privilegia sua dimensão técnica. Nessa perspectiva, ao se persistir na ideia de subordinação dos conselhos de educação às decisões das secretarias, corre-se o risco de se conceber a participação como técnica de gestão no Estado Capitalista, dando legitimidade às decisões unilaterais. Tal aspecto se configura como uma ameaça à ideia de controle democrático, podendo a qualquer momento se efetivar na prática. Nesse sentido, os órgãos de controle social, atualmente, estão sob a ameaça de se transmutarem de espaço público a organismo governamental, como advoga Rodrigues (2010). Faz-se necessária, assim, uma defesa contrária a essa concepção gerencial para não se cair nas armadilhas do pensamento colonizador, que procura a qualquer custo enfraquecer o debate e o poder de decisão dos cidadãos. 


\section{Da legislação Municipal à Função Deliberativa do Conselho Municipal de Educação de MosSoró-RN}

A legislação municipal que regulamenta a institucionalização do Conselho Municipal de Educação de Mossoró-RN consiste em um marco histórico para o município, pois se coloca como ponto de partida para a criação do sistema municipal de ensino e para a democratização por meio da previsão de órgãos colegiados na organização e na gestão dos processos educacionais.

No município de Mossoró-RN, a base legal de criação do sistema municipal de educação precede ao Conselho Municipal de Educação. Por meio desta, é possível identificar funções e responsabilidades do SME. A Lei n. 1.109/97, que institui o Sistema Municipal de Ensino de Mossoró, logo após a Lei de Diretrizes e Bases da Educação brasileira, 9.394/1996, prevê o Conselho Municipal de Educação como órgão do sistema. De forma ilustrativa, a figura a seguir tem como base o Artigo 5, da lei municipal, inciso II, que estabelece que o CME integra os órgãos de ação do sistema e que a sua participação nos processos educacionais se configura em possíveis decisões a serem perpassadas pelo CME, trazendo implicações para o sistema, a secretaria e as escolas.

Figura 1 - Decisões relacionadas com o sistema, a secretaria e as escolas
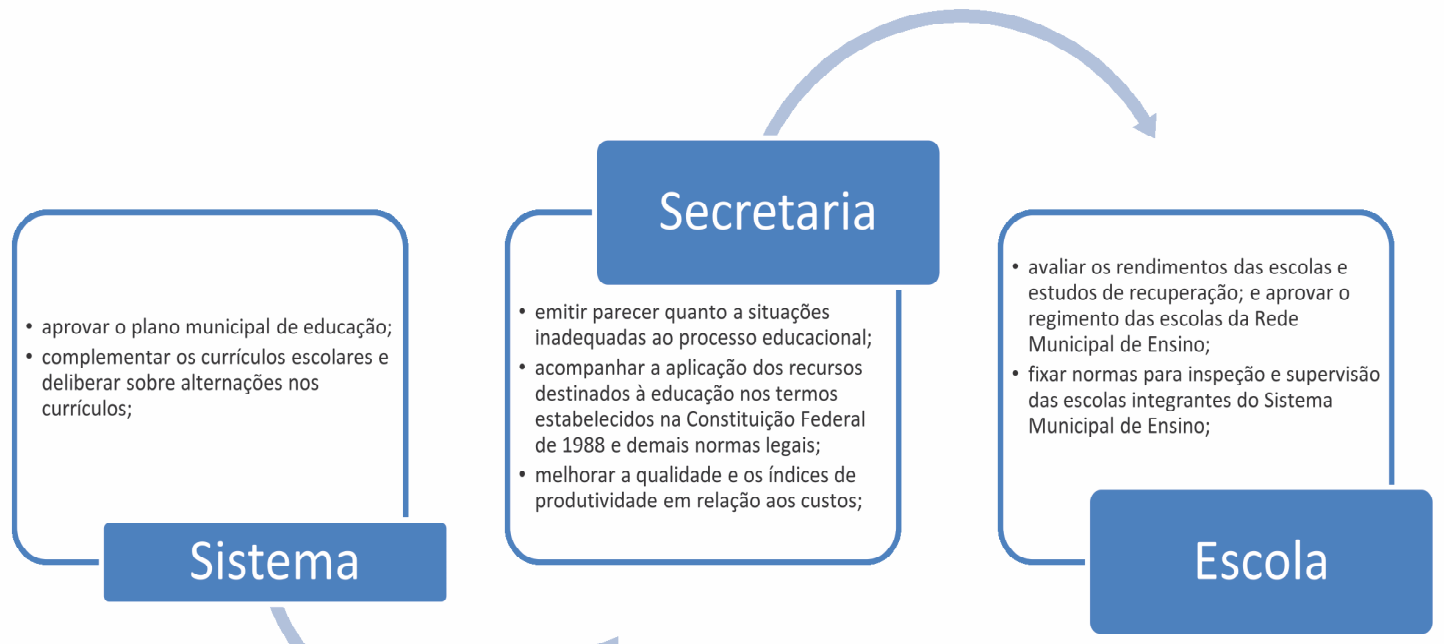

Fonte: Dados da pesquisa de Souza (2013)

Ao se observar a Figura 1, verifica-se que o CME-Mossoró-RN pode agir contribuindo com as decisões do sistema, da secretaria e da escola. Nesse aspecto, Teixeira (2004) afirma que os Conselhos Municipais de Educação possuem função de intermediação entre o Estado e a sociedade, traduzindo ideais e concepções de educação e de sociedade, ao influenciarem a dinâmica das políticas educacionais. Tal fato pode ser observado quando esse órgão colegiado tem competência reconhecida pela lei municipal do sistema para influenciar nas decisões relativas ao Plano Municipal de Educação, ao currículo e à avaliação do desempenho dos alunos.

Sendo assim, as decisões captadas no âmbito da lei que cria o sistema revelam que a função do CME não é isolada, mas está relacionada, pois se direciona tanto para o sistema e para a secretaria quanto para as escolas. No que diz respeito à dimensão do sistema, observa- 
se que o Conselho Municipal de Educação apresenta reconhecida responsabilidade para aprovar o Plano Municipal de Educação, no entanto, isso se confunde com a competência da Câmara dos Vereadores. Entende-se que cabe ao CME participar ou coordenar o processo de elaboração desse documento, bem como submetê-lo à avaliação dos representantes legislativos, pois ao Poder Legislativo é atribuída a responsabilidade pela aprovação de políticas para o município.

Ainda na dimensão do sistema, conforme mostra a Figura 1, verifica-se que a lei municipal que cria o sistema de educação atribui ao CME a tarefa de deliberar sobre a complementação ou a alteração dos currículos escolares. Segundo Chizotti e Ponce (2012, p. 34), o currículo escolar é um instrumento social de responsabilidade coletiva que supõe a participação de cada um. Para os autores, "políticas públicas de currículo da educação básica, que são da responsabilidade imediata dos estados e municípios, têm empreendido iniciativas que quase sempre geram a desvalorização dos sujeitos no processo curricular, o que não nos permitirá chegar a um bom resultado" (CHIZOTTI; PONCE, 2012, p. 34).

Concernente à dimensão da secretaria que se relaciona com o CME, observa-se que a este é atribuída a função normativa e propositiva, quando a Lei Municipal 1.109/1997 destaca que a esse órgão cabe emitir parecer sobre situações inadequadas do processo educacional, bem como melhorar a qualidade e os índices de produtividade em relação aos custos. Ao se abordar a dimensão da escola, a função normativa, mais uma vez, fica evidente, quando se atribuem ao CME a intervenção nos processos de regularização de escolas e a fixação de normas de avaliação de rendimentos. Essas demandas representam um vínculo muito próximo do CME com a secretaria, de modo que essa vinculação ratifica a ação do CME em função do controle do Poder Executivo. Em referência ao acompanhamento dos recursos, previstos constitucionalmente, existe no município de Mossoró o Conselho de Acompanhamento e Controle dos Recursos do FUNDEB, cujo processo de surgimento se deu a partir de uma Câmara no CME, transformando-se, mais tarde, em um conselho próprio.

A Lei que dispõe sobre a criação do Conselho Municipal de Educação de Mossoró-RN, n. 1.110/1997, ratificou e ampliou as funções do CME-Mossoró, cuja iniciativa possibilitou ao município viabilizar uma política de descentralização da educação via $C M E$, que se consubstancia em uma das estratégias da municipalização da educação. Segundo Ribeiro (2004), esse tema é muito debatido e não é novo, posto que, no Brasil, desde 1862, já havia a defesa de um modelo mais autônomo para a educação, viabilizado pelos municípios. Embora tenha sido colocada em prática em algumas experiências isoladas, ainda assim é possível verificar argumentos defensores e contrários à descentralização via municipalização. Em relação aos que defendem essa concepção, suas justificativas se baseiam nos seguintes argumentos: a) maior proximidade com a comunidade; b) democratização da sociedade; c) elemento formador da cidadania civil, política, social; e d) aprimoramento das instituições democráticas. Entretanto, uma corrente contrária à municipalização sustenta que esse processo é vulnerável por vários fatores, destacando-se, dentre eles: a) fragilidade do município brasileiro em relação às práticas clientelistas; b) desoneração e desconcentração de tarefas do Estado; e c) necessidade de reforma tributária. Ora, as conquistas no âmbito das políticas sociais brasileiras, 
em sua maioria, são fruto de longos processos entre projetos progressistas e conservadores, cujos embates nascem em contextos de lutas históricas em defesa de mais direitos sociais. Nesse sentido, os municípios se colocam como entes federativos que conseguiram sobreviver constitucionalmente no federalismo brasileiro.

Em Mossoró-RN, o processo de municipalização tem como ponto de partida a criação do sistema municipal de ensino, em 1997, e foi impulsionado pelo reconhecimento dos órgãos colegiados de gestão, os quais são instrumentos de planejamento democrático, como o Conselho Municipal de Educação e o Plano Municipal de Educação. Nessa perspectiva, o município de Mossoró segue um caminho próprio de organização da educação municipal, contrariando, em certa medida, o percurso histórico da realidade brasileira, que tem se caracterizado pela transferência de encargos financeiros e tarefas dos estados para os municípios.

Do ponto de vista financeiro, segundo a Lei 1.110/1997, o CME-Mossoró possui orçamento para o seu funcionamento vinculado à Secretaria de Educação. Os vínculos com essa secretaria se aproximam cada vez mais, já que o CME funciona no mesmo prédio, localizado em uma sala cedida pelo Centro Administrativo, a qual dispõe de uma mesa e cadeiras acolchoadas para reunião, armários para arquivos, uma linha telefônica, que estava desativada, e uma escrivaninha com computador para a secretária executar as suas atividades. Cabe ressaltar que, diante das atribuições que assume o $C M E$, seu funcionamento cotidiano não pode ficar à deriva das péssimas condições de trabalho.

Durante o processo de realização das entrevistas, foi possível identificar alguns problemas estruturais para o seu funcionamento, destacando-se dentre eles a falta de transporte próprio para deslocamento até as escolas, de secretária permanente, de profissionais especializados e de tempo para os conselheiros se dedicarem ao mandato. Essas dificuldades retratam um pouco da realidade dos CMEs no Brasil, conforme evidenciado no mapa dos Conselhos Municipais de Educação, construído por Souza, Duarte e Oliveira (2013). Outra dificuldade atestada por esses autores consiste na composição de representantes dos segmentos.

Nesse aspecto, os entrevistados foram questionados com o intuito de verificar se a composição do CME-Mossoró influencia na tomada de decisão, pois a relação entre a representação e as decisões que são tomadas reflete certo grau de complexidade entre o que se decide, como se decide e em favor de quais grupos. O acesso à representação no CMEMossoró se dá por meio de indicação de membros do quadro da administração pública e segmentos da sociedade civil. Em relação à presidência, o processo ocorre com a realização de eleição entre os pares. A democratização do acesso dessa presidência representa um avanço quando se considera a realidade nacional, tendo em vista que, em alguns casos, os CMEs têm como presidente o secretário municipal de educação ou conta com a presença do poder executivo, "quer seja mediante o dirigente do órgão municipal encarregado das questões do ensino, que em alguns casos assume a presidência do conselho, quer seja pela presença de um ou mais funcionários designados para tal pelo executivo" (TEIXEIRA, 2004, p. 704).

Os entrevistados, em sua maioria, concordam que a composição do CME contribui para a atuação no município, ao passo que está constituído por representantes tanto da administração pública quanto da sociedade civil. Essa formação corrobora o hibridismo que tem caracterizado a constituição desse órgão colegiado, consistindo em um elemento típico de uma realidade em 
que há mudanças nas relações entre Estado e sociedade, ideia endossada por Avritzer e Pereira (2005) e Santos e Avritzer (2002). Entretanto, essa afirmação dos conselheiros não consegue responder em favor de quais grupos se decide, para que possam encontrar o caminho de uma participação consciente, necessária à reconfiguração da dimensão política e em convergência com a dimensão pedagógica. Essa participação consciente se dá na participação praticada, conforme defende Lima (2003), ou seja, na atuação. Tal atuação é decisiva na medida em que é possível identificar os efeitos externos das decisões mais ou menos latentes, como os de beneficiar ou não a educação no município, conceder ou retirar decisão favorável ao processo de democratização, bem como os padrões de conflitos e as estratégias específicas que dirigem o processo da implementação societária de inovações sociopolíticas.

Com base nos discursos dos conselheiros, é possível extrair algumas interpretações acerca desse processo, visto que a maioria concorda que entre o CME e a Secretaria Municipal de Educação existe uma relação harmoniosa, sem revelar os conflitos internos do processo de tomada de decisão. Ou seja, os conselheiros registram que há uma articulação harmônica não somente entre o CME e a secretaria, mas também entre a rede municipal de ensino, baseada nas escolas que a compõem, quanto a assuntos como: aprovação de ações da secretaria; discussão a respeito do que a secretaria encaminha; sistematização do ensino e funcionamento das escolas; encaminhamento às câmaras do Conselho e desenvolvimento de parceria com o governo, cujas decisões do conselho são tomadas em parceria com a secretaria. Nesse sentido, R1 e R2 afirmam:

[...] a rede municipal de ensino tem uma parceria muito articulada. [...] todo mundo sabe quem é a secretária de educação e quem é a presidente do conselho. [...] tudo que vai ser feito, apesar de ele ser um órgão independente, [...] mesmo assim existe essa comunicação, essa integração entre a secretária e a professora [...], e vice-versa (R1).

[...] A gente tem uma articulação muito boa, é mais de sistematizar o ensino, da forma organizacional. [...] o conselho vem tentando organizar todos os processos das escolas, né? A questão do PPP, a questão do funcionamento das escolas. [...] graças a Deus a gente fechou o ano de 2012 com esses processos quase todos concluídos (R2).

Diante desses discursos, os entrevistados revelaram que há uma proximidade entre os três órgãos do sistema: o $\mathrm{CME}$, a secretaria e a rede municipal de escolas. É como se os conflitos não existissem ou, ao menos, se tornassem opacos diante do Conselho Municipal de Educação. Com base nesse dado, é importante compreender o que aponta o R3 quando considera que um ponto muito forte consiste em ter a sede do CME localizada no mesmo prédio da secretaria:

[...] A própria sede do Conselho fica aqui dentro de nossa secretaria. Esse é um ponto muito forte, muito importante porque está sempre pertinho. O Conselho funciona com sua secretaria ativa, todos os dias o conselho está aberto, por meio da secretaria executiva. A secretária é funcionária [cedida pela secretaria] (R3).

Os discursos dos entrevistados revelam que as circunstâncias do processo de tomada de decisão são montadas em um cenário favorável às deliberações de interesses da Secretaria Municipal de Educação. Desse modo, o resultado dessa articulação parece desembocar em uma relação formal entre o CME e os órgãos do sistema municipal de educação, mas isso não necessariamente ocorre sem problemas, pois, de acordo com Lenhardt e Offe (1984), nem sempre a relação entre as instituições políticas é harmoniosa, principalmente quando a regra do jogo democrático é sempre a opinião da maioria. Ainda que esses representantes 
fossem "superconselheiros, seria necessário explicar em que circunstâncias que os habilitariam a corresponder com medidas políticas e inovações adequadas as exigências identificadas" (SOUZA, 2013, p. 112). Portanto, a indagação sobre se o conselho é órgão da educação no município ou órgão da secretaria de educação torna-se inevitável.

Como tentativa de testar as perguntas anteriormente, os conselheiros foram questionados sobre que tipo de decisão eles vêm sendo chamados a responder, além daquela decisão que tomaram e que mais beneficiou a educação do município. Nesses termos, aparece com maior frequência nos discursos dos conselheiros a participação na elaboração da Lei de Responsabilidade Educacional, conforme mostra a Figura 2.

Figura 2 - Decisão que mais beneficiou a educação no município

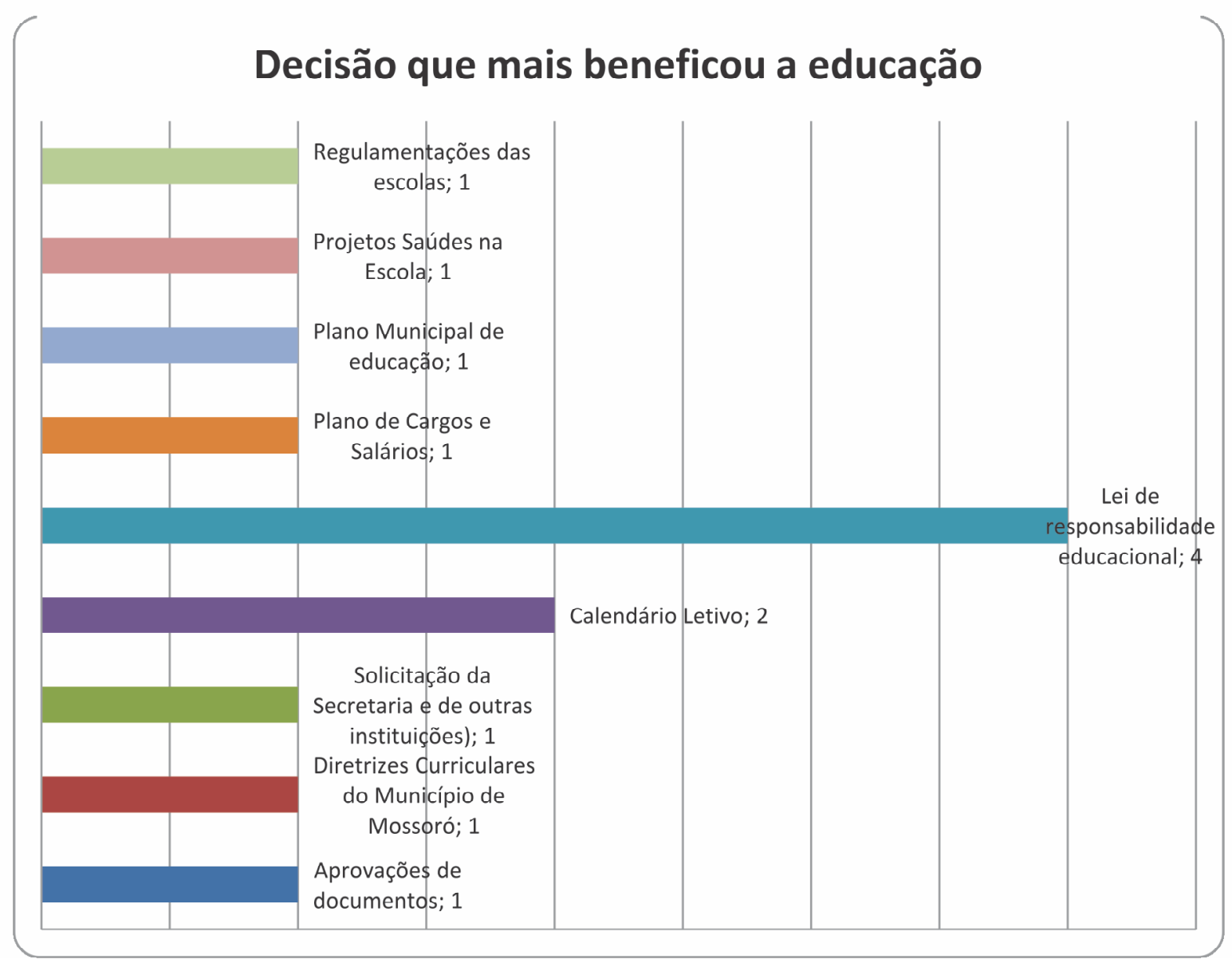

Fonte: Dados da pesquisa de Souza (2013)

Embora os entrevistados atribuam uma maior atenção à concepção da Lei de Responsabilidade Educacional como aquela decisão mais importante do conselho, é fundamental deixar claro que sua aprovação é independente do conselho, pois essa é uma prerrogativa do poder legislativo. Por um lado, o papel do conselho nesse processo se refere ao debate do projeto de Lei, realçando os aspectos favoráveis e contrários à educação ofertada na rede municipal de ensino, uma vez que essa lei não interfere no funcionamento e na organização das escolas privadas. Nesse sentido, as ações do CME têm sido cerceadas pela dominação racional-formal ${ }^{4}$.

De acordo com Mendonça (2000), essa racionalidade procura reforçar a obediência 
às regras para alcançar os objetivos e as metas impostas nos planos e conjuntos de leis. Por outro lado, quando os entrevistados foram questionados sobre a decisão que menos beneficiou a rede municipal, apenas um afirmou que foi a retirada da câmara do FUNDEB, que existia no CME, para a criação do Conselho de Acompanhamento e Controle do FUNDEB. Na época, conforme os entrevistados, esse órgão se constituiu com os mesmos membros do CME. Sendo assim, o conjunto de ações do conselho perpassa por processos que envolvem decisões que podem ser classificadas como simples, como a aprovação de um calendário para a rede municipal de ensino e de pautas de reuniões, até outras decisões que envolvem um maior nível de complexidade, como participar de processos de concepção e acompanhamento de políticas de gestão, formação de professores e de currículo, entre outras.

Na busca por maior compreensão acerca do processo decisório no CME de MossoróRN, os entrevistados foram questionados sobre a possibilidade de ocorrência de discussões antes de o colegiado se reunir. Em suas falas, fica claro que essas discussões ocorrem em algum momento, que pode ser nas reuniões que envolvem todo o conselho, naquelas que acontecem no âmbito das suas câmaras ou ainda nas comissões e nas subcomissões destinadas a estudos e elaboração de pareceres. Essa afirmação se sustenta com base naquilo que eles relataram durante o processo de pesquisa.

A esse respeito, R1 afirma:

Tudo [que] é decidido é discutido antes das reuniões [do conselho]. [...] Quando não são aprovados a gente faz o encaminhamento e ele volta pra aprovação novamente, tá certo? Quando não é aprovado faz o encaminhamento e vai tudo pra discussão. Tudo vai para as comissões, dependendo do tipo de documento que vai aprovar.

O R3 também concorda que há reuniões antes de se discutir qualquer matéria na plenária do conselho, posto que, em seu entendimento,

Há sim, todas. Quando nós encaminhamos qualquer solicitação para o conselho, a senhora presidente, nas reuniões,
encaminha para as subcomissões deacordo coma pauta, comaquele assunto, entãoé encaminhado as subcomissões,
que se reúnem, discutem, apresentam um parecer nas reuniões, por uma reunião específica e as câmaras, elas ficam
nessa incumbência, de competência normal de fazer estudos sobre aquele determinado assunto, encaminham os
pareceres praasenhora presidentequediscutenaAssembleia Geralcomoconselho parabuscarsuas deliberações(R3).

O aspecto a ser considerado nesse momento está na abordagem dos discursos apresentados por R1 e R3, que se referem à antecedência das discussões antes das decisões no conselho, em reuniões nas comissões e nas subcomissões, como forma antecipada das deliberações. Segundo esses conselheiros, as pautas são encaminhadas para as câmaras ou comissões e, após a elaboração dos pareceres, estas retornam para novas reuniões e são submetidas à votação, quando conseguem obter aprovação da maioria. A regra universal da democracia representativa é a decisão fundamentada na maioria, não considerando na maioria dos casos que determinada decisão pode afetar os grupos que ficaram de fora do processo deliberativo, conforme advoga Held (1991). Nesse caso, o critério da maioria não representa novidade em relação à tomada de decisão no CME-Mossoró-RN. O discurso de R3 corrobora a afirmação de R2, quando se refere à anterioridade das discussões quanto ao debate realizado nas câmaras antes da aprovação na plenária, principalmente depois que uma primeira rodada de discussão já foi realizada pelos membros do conselho. 
Sendo assim, R2 detalha que as discussões acontecem depois que a presidente faz abertura da sessão e apresenta a ordem do dia.

As discussões acontecem depois que a presidente do conselho abre a pauta, coloca na ordem do dia o que está em discussão e todos os conselheiros eles têm a vez de dar o seu posicionamento em relação ao que está sendo discutido e cada um coloca o seu posicionamento e depois abre para votação. Quem tiver alguma coisa contra, se coloca contra e quem tiver a favor se coloca a favor e o que tiver contra a gente vai pra novas discussões, vamos rever e vamos estudar a posição do companheiro da gente. [...] Quando é maioria, é claro, vota a favor. Então o caso já tá consolidado. Mas quando não acontece, a gente vai ouvir o companheiro, vamos ver porque que ele tá colocando aquele parecer e a gente vai analisar de uma forma mais detalhada pra gente ter uma visão mais ou menos parecida para o companheiro da gente (R2).

Esse entrevistado faz referência ao processo de discussão nas reuniões do CME e revela aspectos que contribuem para demonstrar que, embora exista um esforço para amortecer os conflitos no processo de decisão, há quem se posicione contrário num determinado momento. Entretanto, esses posicionamentos são levados em consideração para buscar construir consensos entre os conselheiros, com base no critério formal da democracia, por meio da expressão da maioria dos votos apresentados.

Os conselheiros relataram que, quando não há aprovação de um parecer, este retorna às comissões, com o objetivo de realizar mais estudos sobre a matéria e aprofundar discussões sobre os elementos questionados nela. Esse tratamento revela que existe um processo de conscientização dos conselheiros, na medida em que estudam, discutem e votam os processos e as matérias de interesse educacional.

As discussões antes das reuniões somente podem acontecer quando os conselheiros têm acesso às pautas das reuniões com antecedência, caso contrário o processo decisório ficará comprometido e as reuniões do CME se tornarão mais um meio para legitimar decisões preconcebidas pelo sistema. Diante dessa afirmação, os conselheiros foram questionados se essa prática ocorre. Nesse momento, aparecem alguns elementos contraditórios em relação à pergunta anterior, pois, para a maioria dos entrevistados, as pautas não chegam antes das reuniões, como reforça o R1: "Não. Nós não temos. A gente tenta, a [presidente] exige sempre, mas a gente não tem. Só quando ela [a secretária] liga. A secretária liga uma extraordinária, a do mês não".

Os demais entrevistados relatam que não é uma prática comum, pois foi implantada recentemente, sem retratar há quanto tempo isso ocorre.

Às vezes sim, quando são necessários, quando têm conteúdos mais extensos. É necessário que eles mandem a pauta com antecedência que é para gente analisar, fazer a nossa leitura para quando chegar a gente já ter o nosso posicionamento em relação ao conteúdo apresentado (R2).

Quando dá tempo eles enviam, chega o envelopezinho com documento. $E$ às vezes não dá tempo deles enviarem esse material com antecedência, no caso das extraordinárias (R4).

As pautas têm pouco tempo de prática, da pauta chegar antecedentemente. A pauta chega antecedentemente. Mas a prática mesmo era pegar a pauta na hora. Então, a pauta na hora já não possibilita muita análise. Você sabe. Você vê o problema dali e muitas vezes não dava nem para fechar a reunião porque a pauta na discussão, às vezes não chegava nem atingir todos os pontos (R6). 
Com base nas afirmações de R1, R2, R4 e R6, não é recorrente ter acesso à pauta da reunião com antecedência, exceto em alguns casos. Esse processo revela que há risco quando as pautas não são enviadas com mais tempo para que os conselheiros reflitam ou entrem em contato com os representados para ouvi-los a respeito dos assuntos abordados no CME. A exceção ocorre com R5, o qual afirma que chega "Com antecedência! Sempre com antecedência! Correto!", embora não tenha apresentado justificativa.

Ora, conforme já observado, isso consiste em uma contradição, visto que os discursos anteriores possibilitam afirmar que essa prática não é recorrente no Conselho, como bem lembra R4, assumindo que, às vezes, não dá tempo. A disposição de tempo se coloca como uma das dificuldades para que os conselheiros estudem, analisem e cheguem à reunião com uma decisão fundamentada, além de consultar os representados sobre se, de fato, a interpretação do representante Ihes representa. Nesse caso, mais uma vez a questão da representação se relaciona diretamente com a tomada de decisão, pois a hipótese de que determinadas decisões não representam o segmento representado pode ser confirmada. Essa questão requer um aprofundamento, o qual não se possuem condições de fazer nos limites deste trabalho.

Em suma, as reuniões precisam de uma pauta planejada com, no mínimo, uma semana antes das reuniões. Então, o improvável acontece, uma vez que há acesso em casos de extraordinárias, cujas deliberações ocorrem para atender questões emergenciais, como é observado nos ditos dos representantes. Segundo o Regimento do CME, cabe ao presidente do CME "fixar o programa para as reuniões ordinárias e aprovar a Ordem do Dia de cada sessão" (p. 5). Resta saber se o programa é elaborado apenas na perspectiva de existir um cronograma de reuniões com calendário previamente definido, no qual se verifiquem assuntos recorrentes para serem debatidos no CME.

Esses elementos contribuem para a construção de algumas observações, dentre as quais se considera importante destacar que, quando os conselheiros são chamados para refletir sobre as reuniões, estas são classificadas em dois tipos, a saber: ordinárias e/ou extraordinárias. No que concerne às pautas, os representantes as relacionam com assuntos ou temas de necessidade, emergenciais e polêmicos. No contexto de pautas e reuniões, as decisões podem variar entre imediatas e/ou conscientes. Nesse processo, todos podem e devem participar das discussões, concordando ou discordando, para, em seguida, conduzir à votação, o que leva a inferir que o voto consume o processo de tomada de decisão. Nesse sentido, corrobora a conclusão de que o voto se configura como um dos meios clássicos de expressão da decisão da maioria, ao definir quem está autorizado a tomar as decisões coletivas e com quais procedimentos (BOBBIO, 2006).

Os representantes ainda foram levados a refletir se alguma vez já haviam proposto temas, sugestões e/ou opiniões para a discussão no CME, possibilitando que estes sejam ouvidos não apenas na hora do voto, mas também no processo de construção das decisões no que tange à educação municipal. Nessa perspectiva, foi possível averiguar que houve em algum momento a oportunidade para que propusessem temas do cenário nacional, como aconteceu com a discussão sobre a Conferência Nacional de Educação de 
2014, que partiu de um conselheiro, e temas de interesse municipal, tais como: segurança nas escolas, diretrizes curriculares para escolas municipais, prêmio escola de qualidade, orientações para refacção de documentos, eleição para escolher representantes do $\mathrm{CME}$, regulamentação de escolas, normas de avaliação para alunos com deficiência, educação de tempo integral. Entretanto, os entrevistados mais se aproximam da ideia de que estão fazendo sugestões e de que estas são levadas para o plano da negociação, avaliando se são ou não pertinentes ao conselho e à educação no município.

Os representantes foram questionados sobre a interferência da sua participação nas decisões. As respostas mantiveram a heterogeneidade nos discursos, com sucessivas tentativas de harmonização, ou seja, recorrendo ao procedimento do processo democrático. O objetivo foi verificar a interferência da participação praticada pelos sujeitos, conforme Lima (2003), tendo em vista que consiste em um dos critérios de democraticidade via participação direta.

Desse modo, constata-se que, para todos os entrevistados, essa interferência está sempre sujeita à posição da maioria, por meio do debate e da votação. Essa ação não elimina a possibilidade de esse princípio representar a colegialidade de dominação, que ocorre quando se reúnem poderes ou especialistas da administração, aconselhando a administração monocrática na tomada de decisão. Embora os conselhos possam ser considerados aparelhos não monocráticos, a experiência tem demonstrado que eles atuam de forma monocrática, dificultando a possibilidade de transformação em um órgão democrático da educação, para se tornar órgão do sistema de ensino de Mossoró.

No processo de tomada de decisão, é fundamental saber dos representantes se no momento de decidir eles adotam ou não algum critério e o porquê. Esse tipo de questionamento objetiva refletir sobre os critérios de legitimação política e não apenas mostrar que existem critérios. Em linhas gerais, para $50 \%$ dos representantes entrevistados, o principal critério é analisar se a decisão está em consonância com a legislação nacional e local. Outros critérios aparecem dentro desse contexto de entrevistas, quais sejam: $16 \%$ bom senso, $17 \%$ coerência e democratização da informação e $17 \%$ maioria, conforme pode ser observado na Figura 3.

Figura 3 - Critério para tomada de decisão

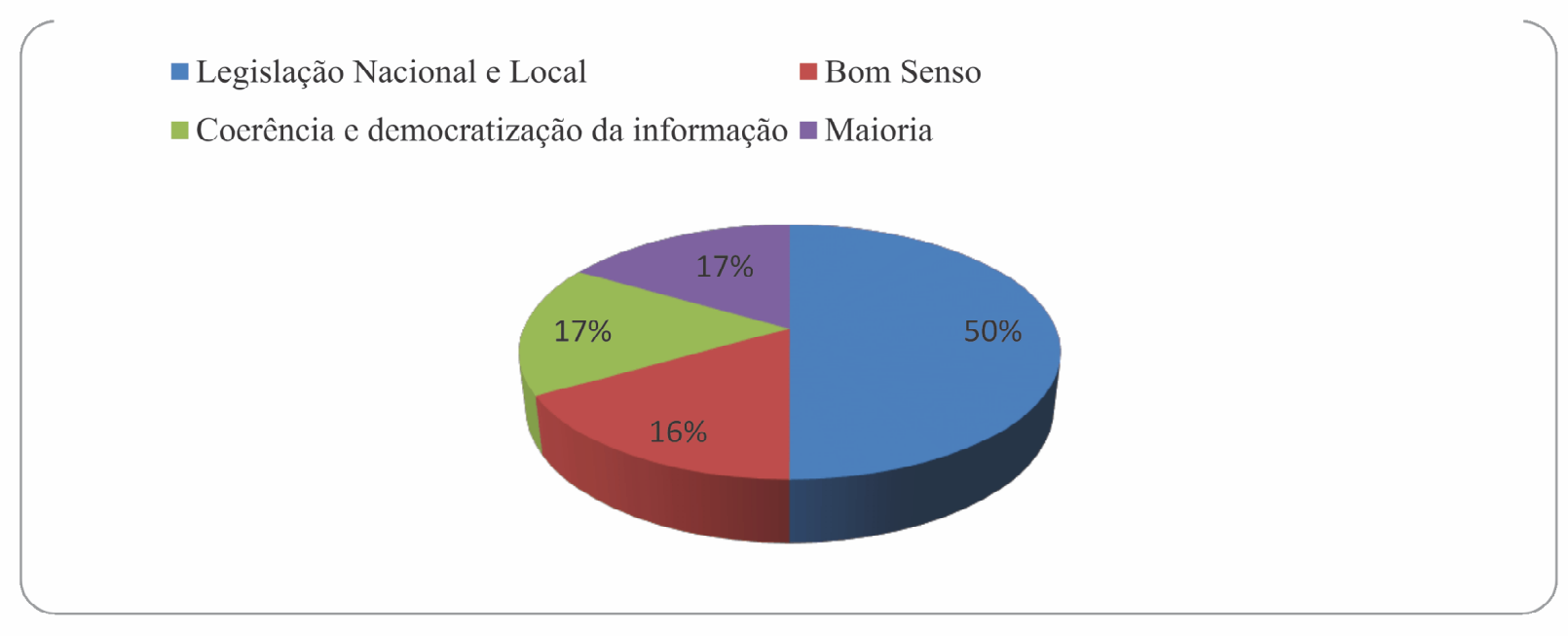

Fonte: Dados da pesquisa de Souza (2013)

Os representantes possuem critérios distintos de decisão que influenciam diretamente na forma como pensam sobre a tomada de decisão no conselho. É perceptível que a metade 
dos representantes entende que as decisões não podem fugir da legislação. No plano da regulamentação, esse tipo de regra está em consonância com o plano formal, cujas decisões estão estruturadas em regulamentos, estatutos, leis.

A análise que pode ser relacionada a esse critério de decisão leva a deduzir que a forma como os representantes chegam às suas funções influencia nos critérios de decisão. A maioria dos representantes teve acesso por meio de indicação, ou do segmento ou da secretaria de educação, o que, para Mendonça (2000), gera um tipo consciência legal para a tomada de decisão baseada na dominação racional.

Outros critérios que emergem das entrevistas estão nas regras não formais de decisão, quais sejam, a regra do bom senso e a regra da coerência. Esses dois critérios podem ser caracterizados como regra não formal, porque são estruturados com base na interpretação local das regras organizacionais, como pode ser observado no discurso do R4. Com isso, também podem carregar consigo as características de critérios informais, visto que, nesse caso, não dispensam os critérios de decisão formal e não formal, mas acrescentam algo a esses dois tipos de critérios decisórios. Entretanto, os representantes confundem o procedimento democrático da maioria como critério para a tomada de decisão. Ou seja, votar somente porque outros estão votando pode significar um risco para a própria democratização no interior do Conselho Municipal de Educação. Mais uma vez, o critério da maioria é evocado pelos conselheiros, consistindo em uma regra universal da democracia representativa. A maioria é critério da democracia representativa, e não critério para a tomada de decisão. Bobbio (2006) alerta para essa questão mostrando que nesse tipo de critério é preciso que aqueles que são chamados a decidir ou a eleger os que deverão decidir sejam colocados diante de várias possibilidades de escolha. Acrescente-se a isso que não se está tratando de realizar qualquer escolha, mas escolhas conscientes. Finalmente, observa-se que os representantes fazem a ponderação da democratização da informação como um critério na tomada de decisão que deve ser levado em consideração.

\section{Considerações Finais}

Estudar a função deliberativa do Conselho Municipal de Educação, a qual consiste na tomada de decisão, é algo bastante complexo, uma vez que são vários os aspectos que entram em cena nesse jogo político de interesses diversos, sendo os mais evidenciados os interesses da Secretaria Municipal da Educação. Foi possível identificar que, nos processos deliberativos, as reuniões e as pautas consistem em um primeiro aspecto da tomada de decisão e que estas passam por um processo de conscientização dos sujeitos sobre as decisões a serem tomadas por meio do voto da maioria. Esse processo se dá nas reuniões de estudos, as quais geralmente acontecem por meio de convocações das câmaras que compõem o conselho ou de calendário previamente definido nas subcomissões que nascem frente à necessidade de discussão a respeito de determinadas matérias.

O agravante do processo de democratização das decisões via Conselho Municipal de Educação diz respeito ao fato de que muitos conselheiros não participam ativamente das reuniões, ficando de fora do processo de decisão, justificando suas ausências, normalmente, pela 
falta de tempo. Infelizmente, a ausência das condições objetivas (falta de tempo, de transporte, de secretária, de infraestrutura adequada, etc.) para assegurar a participação dos conselheiros sejam os titulares, sejam os suplentes - parece traduzir a maneira mais cômoda de manutenção da democracia de baixa intensidade (SANTOS, 2002), favorecendo a condição de controle do Conselho Municipal de Educação de Mossoró-RN. A ideia da possibilidade de uma participação alternada entre os titulares e os suplentes inexiste para suprimir as ausências. Como não há essa possibilidade, o CME funciona com a principal "patologia" da democracia na atualidade, que é ausência dos sujeitos nos processos decisórios, seja pelas dificuldades operacionais, seja pelas dificuldades estruturais que a democracia vivencia nas últimas décadas.

Outra questão importante para uma reflexão crítica refere-se à composição do conselho. Embora existam no quadro representantes da sociedade civil e da administração municipal, ficou evidente que não há decisões sobre assuntos do segmento que eles representam. Além disso, percebeu-se que assuntos de outros segmentos são decididos, como de pais e alunos, porém, na estrutura da composição do $\mathrm{CME}$, não existe representação para estes. Ainda, o conselho sempre consulta o Ministério Público e o sindicato dos servidores da educação, no entanto esses dois segmentos também não possuem assento no CME. A questão da representação deve ser pensada criticamente pelo próprio conselho, frente à necessidade de reformulação ou inserção de novos segmentos.

Todavia, conclui-se temporariamente que, conforme sua atuação, o conselho tem se revelado como um órgão de controle estatal, decidindo mais sobre assuntos da Secretaria de Educação, afirmando-se que a Lei de Responsabilidade Educacional foi a decisão que mais beneficiou a educação no município, deixando marginalizada a importância do Plano Municipal de Educação, mesmo que reconheça sua autonomia relativa para decidir e considere que o conselho foi instituído como mecanismo de democratização do Sistema Municipal de Ensino de Mossoró-RN.

As implicações para um funcionamento adequado aos pressupostos da efetiva democratização do Conselho Municipal de Educação são as mais variadas, conforme se mencionou ao longo deste texto, uma vez que a tomada de decisão é entendida como o processo que busca avançar para além da lógica procedimental, em que a participação não se resume a direito à voz e ao voto, baseado em seus aspectos informais. É fundamental avançar na perspectiva de que os representantes que participam do Conselho Municipal de Educação sejam disseminadores de interesses coletivos, e não apenas de interesses da Secretaria Municipal de Educação. Não sendo assim, o CME se esvai de sua capacidade democrática, para assumir seu papel de órgão que discute, propõe pautas e decide em prol de uma diretriz eminentemente sistêmico-Estatal.

Percebe-se que o CME responde por um conjunto bastante amplo de atribuições que o coloca como órgão colegiado estratégico no planejamento, no acompanhamento e na avaliação de políticas educacionais. Por essa razão, seu funcionamento não pode se dar à deriva das péssimas condições de trabalho dos conselheiros, tampouco dos interesses da Secretaria Municipal de Educação. O CME, como instância consultiva, deliberativa e fiscalizadora, ao assegurar sua condição básica de representar os interesses coletivos, transmuta-se em meio potencializador da democracia na sociedade. 
ALVAREZ, M. C. Controle social: notas em torno de uma noção polêmica. São Paulo em Perspectiva, São Paulo, n. 18, v. 1, p. 168-176, 2004. Disponível em: <http://www.scielo.br/pdf/spp/v18n1/22239. pdf>. Acesso em: 30 mar. 2017. DOI: http://dx.doi.org/10.1590/S0102-88392000000200002

AVRITZER, L.; PEREIRA, M. L. D. Democracia, participação e instituições híbridas. Teoria e Sociedade, Belo Horizonte, número especial "Instituições híbridas e participação no Brasil e na França", p. 14-39, mar. 2005.

BARDIN, L. Análise de Conteúdo. São Paulo: Edições 70, 1977.

BOBBIO, N. O Futuro da Democracia. Tradução de Marco Aurélio Nogueira. São Paulo: Paz e Terra, 2006.

- Estado, Governo e Sociedade: para uma teoria geral da política. Tradução de Marco Aurélio Nogueira: Paz e Terra, 2010.

BOGDAN, R. C.; BIKLEN, S. K. Investigação Qualitativa em Educação. Tradução de Maria João Alvarez, Sara Bahia dos Santos e Telmo Mourinho Baptista. Porto: Porto, 1994.

CHIZOTTI, A.; PONCE, B. J. O currículo e os sistemas de ensino no Brasil. Currículo Sem Fronteiras, v. 12, n. 3, p. 25-36, set./dez. 2012. Disponível em: <http://www.curriculosemfronteiras.org/ vol12iss3articles/chizzotti-ponce.pdf>. Acesso em: 30 mar. 2017.

CONSELHO MUNICIPAL DE EDUCAÇÃO DE MOSSORÓ. Regimento Interno do Conselho Municipal de Educação de Mossoró. Mossoró, 1997.

FRANCO, M. L. Análise de Conteúdo. 3. ed. Distrito Federal: Líber Livros, 2008. (Série Pesquisa v. 6).

GADOTTI, M. Sistema Municipal da Educação: estratégias para a sua implementação. Centro de Referência Paulo Freire. Instituto Paulo Freire. s/d. Disponível em: < http://www.acervo.paulofreire. org:8080/xmlui/bitstream/handle/7891/3396/FPF_PTPF_01_0419.pdf>. Acesso em: 30 mar. 2017.

HELD, D. A democracia, o Estado-Nação e o sistema global. Lua Nova, São Paulo, n. 23, p. 145-194, mar. 1991.

IBGE. INSTITUTO BRASILEIRO DE GEOGRAFIA E eSTATÍSTICA. Perfil dos Municípios Brasileiros: 2009. Ministério do Planejamento, Orçamento e Gestão. Diretoria de Pesquisas. Coordenação de População e Indicadores Sociais. Rio de Janeiro: IBGE, 2010.

JANEIRA, A. L. A técnica de análise de conteúdo nas ciências sociais: natureza e aplicações. Análise Social, Lisboa, 2. sér., v. 9, n. 39, p. 370-399, 1972.

LENHARDT, G.; OFFE, C. Tentativas de explicação político-sociológica para as funções e os processos inovadores da política social. In: OFFE, C. Problemas estruturais do Estado Capitalista. Tradução de Bárbara Freitag. Rio de Janeiro: Tempo Brasileiro, 1984. p. 09-53.

LMA, L. A escola como organização educativa: uma abordagem sociológica. 2. ed. São Paulo: Cortez, 2003.

MENDONÇA, E. F. A regra e o jogo: democracia e patrimonialismo na educação brasileira. Campinas: FE/Unicamp, 2000.

. Estado patrimonial e gestão democrática do ensino público no Brasil. Educação e Sociedade. Educação \& Sociedade, São Paulo, ano XXII, n. 75, ago. 2001. Disponível em: < http://www.scielo.br/ 
pdf/es/v22n75/22n75a07.pdf>. Acesso em: 24 abr. 2017.

MORAES, R. Análise de conteúdo. Revista Educação, Porto Alegre, v. 22, n. 37, p. 7-32, 1999.

PREFEITURA MUNICIPAL DE MOSSORÓ. Lei 11.110/1997. Dispõe sobre o Conselho Municipal de Educação, e dá outras providências. Palácio da Resistência, Mossoró, 1997.

RIBEIRO, W. Municipalização: os conselhos municipais de educação. Rio de Janeiro: DP\&A, 2004. 118 p.

RODRIGUES, M. M. De espaço público a organismo governamental: transmutações de mecanismos de participação popular. Revista HISTEDBR, Campinas, n. 39, p. 153-168, set. 2010.

SANTOS, B. S.; AVRITZER, L. Introdução: para ampliar o cânone democrático. In: SANTOS, B. S. (Org.). Democratizar a democracia: os caminhos da democracia participativa. Rio de Janeiro: Civilização Brasileira, 2002. p. 39-78.

SOUZA, A. S. Estudo sobre tomada de decisão no Conselho Municipal de Educação de MossoróRN (1997-2010). 2013. 166f. Dissertação (Mestrado em Educação) - Universidade do Estado do Rio Grande do Norte, Mossoró, 2013.

SOUZA, D. B.; DUARTE, M. R. T.; OLIVEIRA, R. F. CMEs no Brasil: uma cartografia a partir dos estudos teórico-empíricos. In: SOUZA, D. B. (Org.). Mapa dos Conselhos Municipais de Educação no Brasil. São Paulo: Loyola, 2013. p. 23-55.

TEIXEIRA, L. H. Conselhos Municipais de Educação: autonomia e democratização do ensino. Cadernos de Pesquisa, São Paulo, v. 34, n. 123, p. 691-708, set./dez. 2004. Disponível em: < http://www.scielo. br/pdf/cp/v34n123/a09v34123.pdf>. Acesso em: 30 mar. 2017.

Artigo recebido em: $27 / 08 / 2017$ Aprovado em: 25/10/2017

Contato para correspondência: Allan Solano Souza.

E-mail: asolanosouza@gmail.com

1 No Brasil, não há um sistema nacional de educação, pois estados e municípios se anteciparam e criaram subsistemas como estruturas justapostas, de acordo com a concepção de Gadotti (s/d). Com base nisso, "um sistema nacional pressupõe a articulação e não a justaposição, nem a anulação de um sistema por outro" (GADOTTI, s/d, p. 1). Por essa razão, o autor afirma que os sistemas educacionais nasceram com a necessidade de tornar a atividade educacional intencional.

2 Neste texto, a educação local está sendo compreendida como aquela de responsabilidade constitucional atribuída ao município.

3 Essa expressão foi cunhada pela Sociologia norte-americana, no século XX, em autores como George Herbert Mead (1863-1931) e Edward Alsworth Ross (1866-1951), para apreender os mecanismos de cooperação e de coesão voluntária da sociedade norte-americana, cujos autores estavam mais interessados em encontrar as razões da coesão social, tendo em mente uma preocupação mais microssociológica. Após a Segunda Guerra Mundial, os estudos no campo da Sociologia e da História passam a se interessar mais pelas questões macrossociológicas, como a da relação do Estado com os mecanismos de controle social. A coesão social passa a ser vista como "resultado de práticas de dominação organizadas pelo Estado ou pelas classes dominantes" (ALVAREZ, 2004, p. 170). Na modernidade, Michel Foucault, embora não utilize a expressão 
controle social de modo significativo, pode ser considerado como o teórico que mais busca se aproximar de uma perspectiva mais complexa, cujo foco tem se concentrado nas práticas de poder produtoras de comportamentos, formas de saber e formas de subjetividade (ALVAREZ, 2004, p. 171).

4 Embora Mendonça esteja tratando de colegiados escolares e sua relação com a direção escolar, tecendo críticas à concepção de estado patrimonial e colocando como alternativa a este os caminhos da gestão democrática, é possível refletir de forma análoga aos conselhos de educação. Por essa razão, faz sentido a sua afirmação, quando diz: "A maneira cartorial como são constituídos alguns colegiados tem levado ao seu funcionamento inadequado. Apesar do poder formal que possuem essas instâncias no encaminhamento de diferentes situações da convivência escolar, muitas vezes ele não é exercido por falta de consciência dos conselheiros em relação a esse poder" (MENDONÇA, 2001, p. 91). 